\section{Soviet science}

\section{Too many at the top}

THE Soviet Union's "sectoral" research establishments - the institutes, laboratories and design centres that belong neither to the universities nor to the Academy network - have failed to respond to Mr Gorbachev's call for streamlining and restructuring. Reporting to the Supreme Soviet last week, Nikolai Ryzhkov, chairman of the USSR Council of Ministers, noted that some of these institutes had virtually ceased to do science altogether and had become little more than "managerial adjuncts" of the ministries to which they are attached.

During the past 20 years, the network of sectoral institutes has proliferated, as $\mathrm{Mr}$ Gorbachev pointed out during the General Committee plenary meeting in June 1985. As a rule, interministerial bureaucratic barriers made the sharing of facilities impractical or impossible, while some establishments seem to owe their origin to the empire-building propensities of certain ministries. Mr Gorbachev therefore called for the closure of redundant, inefficient or outdated sectoral institutes, and the establishment of inter-sectoral scientific and technical complexes that would cut across ministerial barriers and, at the same time, link research facilities with production enterprises. At the same time, a massive injection of finance into science was promised. Annual expenditure (excluding capital outlay) is to rise from 24,800 million rubles in 1985 to 33,000 million rubles in 1990 . Capital investment in science will rise by 70 per cent over the same period.

The ministries, however, failed to respond to the challenge. Instead, they leapt to the defence of the institutes threatened by $\mathrm{Mr}$ Gorbavhev's attack, even if, for years, they had shown no interest in how these institutes were working. In the end, Ryzhkov told the Supreme Soviet, the Council of Ministers had to intervene and close down some of the most blatantly inefficient establishments. He cited two such cases. The All-Union Research and Design Institute for Complex Technological Processes, which belonged to the Ministry of Chemical and Petroleum Machine Building consisted, at the time of its closure, of 71 "ordinary personnel" and no less than 176 "leaders of different ranks", while out of its 130 research projects, only one or two had any scientific relevance. Likewise, one of the design institutes of the Ministry of the Machine Tool and Tool-Making Industry, which employed 600 people at the time of its closure, had managed to produce inventions from only two of its projects.

Vera Rich

Telecommunications

\title{
Japanese cable competition
}

\section{Tokyo}

INTERNATIONAL telecommunications in Japan are booming. Annual growth in volume is $20-30$ per cent, and in the past few weeks two giant consortia have emerged that hope to grab a slice of this market, currently worth more than 200,000 million yen ( $£ 800$ million) a year but monopolized until now by Kokusai Denshin Denwa (KDD). KDD, in turn, has announced plans to lay two submarine optical fibre cables to provide high-capacity digital links between Japan and the American and Asian continents by 1990 .

Japan's telecommunications laws were liberalized more than a year ago. Five domestic telecommunications companies have been set up to compete with Nippon Telegraph and Telephone Corporation (NTT) in the domestic market, but in the past month a spate of announcements have heralded competition in the international arena.

First off the mark were the three former zaibatsu trading houses, Mitsubishi Corporation, Mitsui \& Co. and Sumitomo Corporation, which will set up a feasibility study company next month as a first step towards forming their so-called "second KDD". The consortium will lease transponders of Intelsat satellites from KDD, Japan's Intelsat representative.

Next, C. Itoh \& Co., a trading house rival of the zaibatsu group, announced plans to establish a new international telecommunications company jointly with Toyota, General Motors of the United States and Britain's Cable \& Wireless. This consortium intends to lay its own submarine trans-Pacific optical fibre cable in direct competition with that of KDD.

Both consortia have capital investment links with Japan Communication Satellite, one of the five new domestic telecommunications companies, and so will have ready access to a domestic carrier.

The KDD submarine cable network will be built in collaboration with American Telephone and Telegraph, Korea Telecommunication Authority and, surprisingly, Cable \& Wireless (Hong Kong) Ltd. Two branching cables will be laid.

The first, trans-Pacific cable 3 , to be completed by late 1988 , will link Japan, Guam, Hawaii and the US mainland via a submarine branching point about $1,500 \mathrm{~km}$ north of Guam. More than 13,000 km of cable will be laid along the seafloor which plunges to depths of over $8000 \mathrm{~m}$ in the trenches that rim the western Pacific in an arc between Guam and Japan. The second cable will run off the Pacific coast and split north of Okinawa, with one branch running to South Korea, the other to Hong Kong.

The total cost of the two cables will be a staggering $\$ 800$ million ( $£ 530$ million), but with 7,560 channels, the trans-Pacific 3 cable will have about ten times the capacity of the two existing coaxial cables and will be on a par with Intelsat satellites which currently have 6,000 or 12,000 telephone channels. Digitilization will allow high-speed data transmission, video transmission and teleconferencing — capabilities that were formerly the preserve of satellites. At present about 60 per cent of KDD's international transmissions are via Intelsat satellites, but this percentage is expected to drop substantially.

Once in place, maintenance costs for the cables should be low, provided submarine slides, fishing trawls or unwary research vessels do not break them - not uncommon events off Japan's coast. For example, in 1972 turbidity current severed the trans-Pacific cable in Sagami Bay and in 1984 the Natsushima, mother ship of Japan's deep-sea submersible Shinkai 2000 , managed to do the same thing at a cost to KDD of Y52 million (negotiations for compensation are proceeding), while the Japan-China submarine cable has been fished up so often by trawlers it has had to be buried $70 \mathrm{~cm}$ below the seafloor using a special cable-laying device equipped with a plough. But barring such accidents, the submarine cable can be expected to have a lifetime of at least 20 years.

The plan of the $C$. Itoh consortium to lay a competing trans-Pacific optical fibre cable is meeting resistance. KDD considers it to be "unfair competition" because, as a public entity, KDD has a responsibility to maintain parallel systems (satellite and cables) to ensure continuity of service if one system broke down, whereas the "third KDD" plans to use only cable.

KDD further argues that there is simply not enough room for three competitors in Japan's international telecommunications market. Critical in this argument is the future size of the market. Whereas KDD estimates it will amount to 600,000 million yen by 1995, a survey released by the Federation of Economic Organizations (Keidanren) thinks it will be twice that. Competition will influence market value. If rates are slashed, market value growth will not match the growth in telecommunications volume.

The fate of the third KDD thus remains uncertain. Toyota has made no clear commitment to join the consortium, and officials at the Ministry of Post and Telecommunications echo KDD's view that "two's company, three's a crowd". The consortium, however, may simply have been floating a trial balloon.

David Swinbanks 